\title{
Signaling Potential Therapeutic Herbal Medicine Prescription for Treating COVID-19 by Collaborative Filtering
}

\author{
Fan Yang ${ }^{1,2}$, Qi Zhang ${ }^{1,2}$, Zhongshang Yuan ${ }^{1,2}$, Saisai Teng ${ }^{3,4 *}$, Lizhen Cui ${ }^{3,4}$, Fuzhong Xue ${ }^{1,2}$ \\ and Leyi Wei ${ }^{3,4 *}$ \\ ${ }^{1}$ Department of Epidemiology and Biostatistics, School of Public Health, Cheeloo College of Medicine, Shandong University, \\ Jinan, China, ${ }^{2}$ Institute for Medical Dataology, Cheeloo College of Medicine, Shandong University, Jinan, China, ${ }^{3}$ School of \\ Software, Shandong University, Jinan, China, ${ }^{4}$ Joint SDU-NTU Centre for Artificial Intelligence Research (C-FAIR), Shandong \\ University, Jinan, China
}

\section{OPEN ACCESS}

Edited by:

Chandrabose Selvaraj,

Alagappa University, India

Reviewed by:

Talha Bin Emran,

Begum Gulchemonara Trust

University, Bangladesh

Gopinath Krishnasamy,

University of Turku, Finland

*Correspondence:

Saisai Teng

202015209@mail.sdu.edu.cn

Leyi Wei

weileyi@sdu.edu.cn

Specialty section:

This article was submitted to Translational Pharmacology,

a section of the journal

Frontiers in Pharmacology

Received: 26 August 2021 Accepted: 17 November 2021 Published: 24 December 2021

Citation:

Yang $F$, Zhang $Q$, Yuan Z, Teng $S$, Cui L, Xue Fand Wei L (2021) Signaling Potential Therapeutic Herbal Medicine Prescription for Treating COVID-19 by Collaborative Filtering.

Front. Pharmacol. 12:759479.

doi: 10.3389/fphar.2021.759479
Severe acute respiratory syndrome coronavirus 2 (SARS-CoV-2) has aggressed in more than 200 countries and territories since Dec 2019, and 30 million cases of coronavirus disease 2019 (COVID-19) caused by SARS-CoV-2 have been reported, including 950,000 deaths. Supportive treatment remains the mainstay of therapy for COVID-19. There are no small-molecule-specific antiviral drugs available to prevent and treat COVID-19 until recently. Herbal medicine can facilitate syndrome differentiation and treatment according to the clinical manifestations of patients and has demonstrated effectiveness in epidemic prevention and control. The National Health Commission (NHC) of China has recommended "three TCM prescriptions and three medicines," as a group of six effective herbal formulas against COVID-19 in the released official file "Diagnosis and Treatment Protocol for COVID-19 Patients: Herbal Medicine for the Priority Treatment of COVID-19." This study aimed to develop a collaborative filtering approach to signaling drug combinations that are similar to the six herbal formulas as potential therapeutic treatments for treating COVID-19. The results have been evaluated by herbal medicine experts' domain knowledge.

Keywords: collaborative filtering, COVID-19, SARS-CoV-2 proteins, traditional herbal medicine, small molecule docking

\section{INTRODUCTION}

The novel coronavirus disease 2019 (COVID-19) pandemic caused by SARS-CoV-2 continues to cause a rush threat to global health. The outbreak that started in early December 2019 has spread worldwide. As of October 2nd, 2021, the overall number of patients confirmed to have the disease has exceeded 235,063,766 in more than 180 countries, though the number of people infected is probably much higher. More than 4,805,700 people have died from COVID-19. ${ }^{1}$ This pandemic is ongoing, so quickly identifying new preventive and therapeutic agents is a top priority.

Although SARS-CoV-2 is widespread and causes multiple organ damage, no specific antiviral drugs or vaccines are currently available. Development of these treatments usually takes a long period, meaning that a more immediate treatment should be found if at all possible. A report issued

${ }^{1}$ https://www.worldometers.info/coronavirus/. 
TABLE 1 | Clinical features of COVID-19.

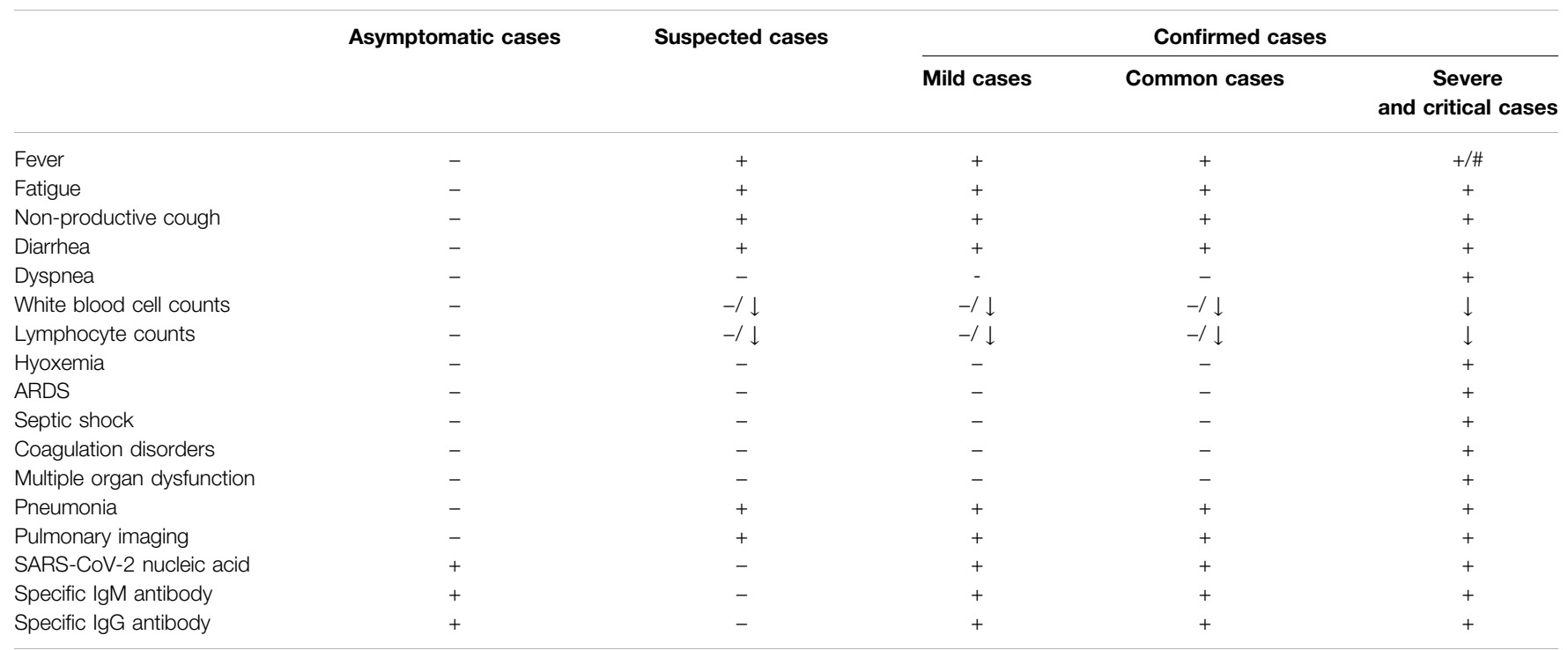

Note: "+" means positive index; "-" means negative index; "\#” means some severe patients with no fever symptom; " $\downarrow$ " means decreasing index.

TABLE 2 | Top 10 compounds without ADME screening.

Index Mol Compound

$1 \quad$ MOL001479 Chelidimerine

2

MOL007062 Neo-przewaquinone a

3

MOL004227 Sanguidimerine

4

MOL005085 Chelidimerine

5

MOL012727 Mulberrofuran K

6

MOL012728 Mulberrofuran M

MOL008559 (2aR,2'R,4R,6aR,6bS,8aS,8bR,11as, 12aR,12bR)4-((S)-2-(2,6-dimethylphenyl)propoxy)-5',5',6a,8atetramethyl-8-methylenedocosahydro- $1 \mathrm{H}$-spiro [pentaleno[2,1-a]phenanthrene-10,2'-pyran]

8 MOL002041 C-Curarine
Molecular structure

Free energy

$-10.73$

Greater Celandine Herb
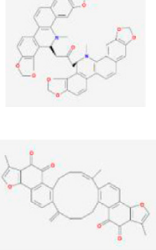

$-10.21$

Salvia miltiorrhiza

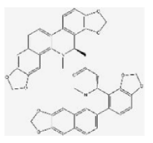

$-9.71$

Corydalis Corydalis

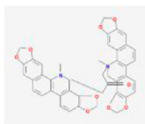

$-9.55$

Shinyleaf Pricklyash Root

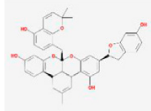

$-9.4$

White Mulberry Root-bark

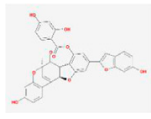

$-9.34$

White Mulberry Root-bark

$-9.29$

Puncturevine Caltrop Fruit

and

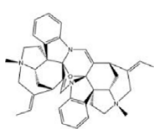

$-9.27$

Chinese Arborvitae Twig 
TABLE 2 | (Continued) Top 10 compounds without ADME screening.

\begin{tabular}{|c|c|c|c|c|c|}
\hline Index & Mol & Compound & Molecular structure & Free energy & $\begin{array}{c}\text { Major presence } \\
\text { of herb }\end{array}$ \\
\hline 9 & MOL011100 & Bisindigotin & & -9.24 & Indigoplant Natural Indigo \\
\hline 10 & MOL007238 & Physalinb & & -9.21 & Franchet Groundcherry Calyx and Fruit \\
\hline
\end{tabular}

by the World Health Organization (WHO) presented that the herbal medicine could be a potentially valuable resource to this end. $^{2}$ The effectiveness of herbal treatment in controlling contagious disease is demonstrated during the 2003 severe acute respiratory syndrome (SARS) outbreak (Chen and Nakamura, 2010).

The summarized clinical features of COVID-19 are shown in Table 1. The SARS-CoV-2 infected patients are categorized into different types such as asymptomatic cases, suspected cases, and confirmed cases (Li et al., 2020a). In order to analyze infected patients directly, the clinical features of COVID-19 are only taken from confirmed symptomatic infected patients without considering the asymptomatic and suspected patients. The confirmed cases can be divided into mild cases, common cases, and severe cases because of their different clinical manifestations. Patients with mild symptoms are characterized by low-grade fever and mild fatigue. The most common features of COVID-19 are fever, fatigue, cough, and bilateral distribution of ground-glass shadows under chest CT scan imaging (Ning et al., 2020). In addition, some patients also exhibited runny nose, sore throat, and diarrhea (Huang et al., 2020). Symptoms of dyspnea and hypoxemia appeared in severe cases after a week onset, rapidly deteriorating into ARDS, septic shock, coagulation dysfunction, and multiple organ failure (Huang et al., 2020).

The aforementioned symptoms of COVID-19 are similar to those explained in the medical book of HuangDi Neijing (Cavalieri and Rotoli, 1997), for plague category, being highly infectious and epidemic. COVID-19 could be classified into colddampness epidemic (a disease caused by internal abundance of the cold-damp pestilential pathogen) (Zhao et al., 2021). It is proposed that the direct cause of this disease is the invasion of evil $Q i$, and basic cause is the insufficiency of vital $Q i$, as well as the abnormal external environment at the end of 2019 (Zeng, 2020). Referring from the epidemic, COVID-19 can be divided into four stages: the early stage with symptoms of cold-dampness evils attacking the lung and spleen, the middle stage with symptoms of cold-dampness evils obstructing the lung and spleen, the late stage with symptoms of cold-dampness evils closing the lung and injuring spleen, and the recovery stage with symptoms of Qideficiency of the lung and spleen (Zeng, 2020).

${ }^{2}$ https://www.afro.who.int/news/expert-panel-endorses-protocol-covid-19-herbalmedicine-clinical-trials.
Ren et al. (2021) compared the corresponding pathogenesis of SARS-CoV-2 infection with the perspective of small-molecule drugs, which is also shown in Figure 1. In the mild stage, SARS$\mathrm{CoV}-2$ replication occurred in the trachea, which may be incubated for 5-6 days (Wölfel et al., 2020). After that, there is a mild symptom for $80 \%$ of infected patients, mainly including fever and dry cough, which disappeared spontaneously within 6-10 days (Li et al., 2020b; Chan et al., 2020), whereas around $20 \%$ of patients developed viral infection from the trachea to the lungs (Li et al., 2020b). SARS-CoV-2 binds with targets in alveolar epithelial cells such as ACE2 and TMPRSS2, and induces apoptosis response associated with vascular leakage (Dong et al., 2020). This leakage causes the first wave of local inflammation and recruits immune cells from the blood into the lungs, thereby eliminating extracellular viruses and destroying infected cells (Shi et al., 2020). In this stage, the disease may rapidly develop into severe illness manifested as acute respiratory distress syndrome, acute lung injury, multiple organ dysfunction, and septic shock (Perico et al., 2021). During the recovery stage, it is reported that some patients still have clinical manifestations such as cough, fatigue, poor appetite, and abnormal mood, which need more time to be recovered completely. In terms of the comprehensive contrastive analysis, herbal medicines have a similar treating process with small-molecule drugs.

A definitive therapeutic agent for managing COVID-19 has not been recommended for humans until now. Current preventive and treatment efforts for COVID-19 have focused on developing vaccines and specific therapeutic agents targeting SARS-CoV-2 (Dhama et al., 2020). Although Food and Drug Administration (FDA)-approved antiviral drugs and several types of vaccines are currently available, many alternative treatments are still being proposed as an adjunctive treatment for COVID-19. It has been reported that herbal medicines could be considered an alternative approach for the treatment and prevention of COVID-19 (Remali and Aizat, 2020). More systematic review articles also concluded that herbal medicine showed significant effects in increasing the total effective rate and alleviating the symptoms (Ang et al., 2020; Liu et al., 2020).

Although the use of herbal medicine for COVID-19 is an effective treatment, designing herbal medicine from scratch is costly and time-consuming. In such a case, we borrowed the idea from drug repurposing to mining potential therapeutic herbal formulas by developing a collaborative filtering approach. Drug repurposing is the strategy that given drugs with a known 

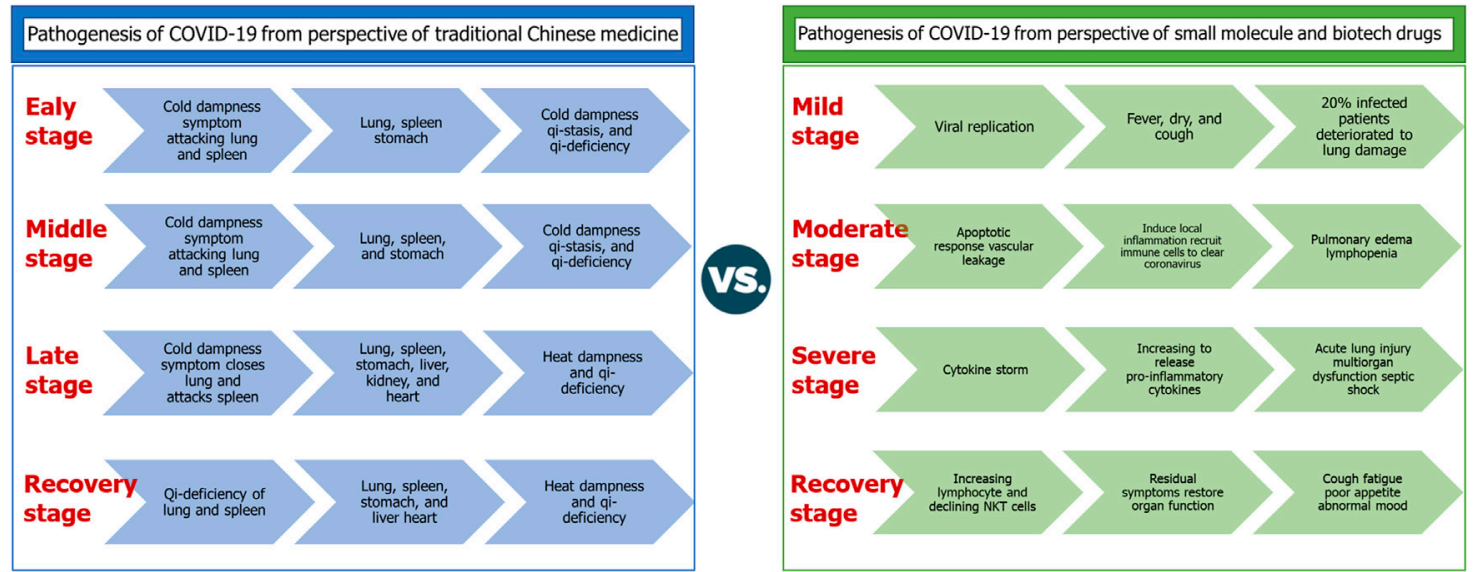

FIGURE 1 | Compared pathogenesis of COVID-19 from herbal medicines and small-molecule drugs.

mechanism of action and pharmacokinetics can be considered the priori knowledge of a specific domain. When the potential effects of the known drug are discovered, it makes the drug more effective and safer to be used, without having to start from scratch.

\section{METHODS}

\section{Molecular Docking}

\section{The Significance of Molecular Docking}

Molecular docking is the process of mutual recognition between two or more molecules through geometrical complementarity and energy matching. Geometric complementarity is the match in shape between molecules, and energy complementarity is the analysis of the interaction forces between molecules. Molecular docking can be used to predict the binding conformation of small molecules of compounds in biological macromolecules and their binding ability, and plays an important role in the study of protein-ligand interaction mechanisms and structure-based computer-aided herbal medicine design (Khodair et al., 2021). To date, this method is still used for rapid screening of compounds from a compound library containing thousands of compounds, saving significant time and cost for herbal medicine discovery and development (Ewing and Kuntz, 2015). Therefore, in this study, the molecular docking technique is chosen to synthesize the binding conformation between molecules.

\section{Scoring Functions}

Common molecular docking software includes AutoDock Vina, AutoDock4, and QVina. In this study, we use QVina for molecular docking, which is a new docking tool that utilizes the powerful scoring function of AutoDock Vina and the accelerated search algorithm of QVina to increase the search space, and it has very good results for blind docking. The purpose of molecular docking is to find the best binding mode between ligand and receptor molecules (Hassan et al., 2020). Therefore, the most important problem faced is how to evaluate the binding strength between docked molecules. In this study, we combine certain advantages of knowledge potential and empirical scoring functions for derivation, extracting empirical information from conformational preferences and experimental affinity measurements of receptors and ligands, and thus deriving a scoring function for the binding affinity of herbal medicine compounds and SARS-CoV-2 proteins. Specifically, the scoring function $\mathrm{c}$ is calculated using the following equation (Quiroga and Villarreal, 2016):

$$
c=\Sigma_{i<j} f_{t_{i} t_{j}}\left(r_{i j}\right) .
$$

Each atom $i$ is assigned a type $t_{i}$, and each atom $\mathrm{j}$ is assigned a type $t_{j}$. Then the symmetric interaction function $f_{t_{i} t_{j}}$ of the distance $r_{i j}$ between atoms is defined. Furthermore, the scoring function can be obtained from the $h_{t_{i} t_{j}}$ function of the weighted sum of spatial interactions. Functions $h_{t_{i} t_{j}}$ include all pairs of atoms with different weights, hydrophobic interactions between hydrophobic atoms, and hydrogen bonding forces.

$$
\begin{aligned}
& \mathrm{f}_{\mathrm{t}_{\mathrm{i}} \mathrm{t}_{\mathrm{j}}}\left(\mathrm{r}_{\mathrm{ij}}\right)=\mathrm{h}_{\mathrm{t} \mathrm{t}_{\mathrm{j}}}\left(\mathrm{d}_{\mathrm{ij}}\right), \\
& \mathrm{d}_{\mathrm{ij}}=\mathrm{r}_{\mathrm{ij}}-\mathrm{R}_{\mathrm{t}_{\mathrm{i}}}-\mathrm{R}_{\mathrm{t} j \mathrm{j}},
\end{aligned}
$$

where $R_{t}$ is the Van der Waals radius of a t-type atom.

The spatial interaction distances for the molecular docking process can be obtained using Gaussian distances (Eqs 4, 5). If both molecules in the docking matrix are hydrophobic, it can be calculated using Eq. 6. The repulsion of molecules can be calculated using Eq. 7. If the molecule is composed of a hydrogen bond donor and a hydrogen bond acceptor, Eq. $\mathbf{8}$ is added to the calculation.

$$
\begin{gathered}
\operatorname{Gauss}_{1}(d)=e^{-(d / 0.5 \AA)^{2}}, \\
\operatorname{Gauss}_{2}(d)=e^{-(d-3 \AA / 2 \AA)^{2},} \\
\text { Hydrophobic }(d)=\left\{\begin{array}{cc}
1, & d<0.5 \AA \\
1.5 \AA-d, & 0.5 \AA \leq d \leq 1.5 \AA \\
0, & d>1.5 \AA
\end{array}\right.
\end{gathered}
$$




$$
\begin{gathered}
\text { Repulsion }(d)=\left\{\begin{array}{cc}
d^{2}, & d<0 \\
0, & d \geq 0
\end{array}\right. \\
\text { Hydrogen bonding }(d)=\left\{\begin{array}{cc}
1, & d<-0.7 \AA \\
\frac{d}{0.7 \AA}, & -0.7 \AA \leq d \leq 0 \\
0, & d>0
\end{array}\right. \\
h_{t_{i} t_{j}}=\left\{\begin{array}{c}
w_{1} * \text { Gauss }_{1}(d)+w_{2} * \text { Gauss }(d)+w_{3} * \text { Repulsion }(d)+ \\
w_{4} * \text { Hydrophobic }(d)+ \\
w_{5} * \text { Hydrogen bonding }(d)
\end{array}\right.
\end{gathered}
$$

$$
\begin{aligned}
R_{t}: w_{1}= & -0.035579, w_{2}=-0.005156, w_{3}=0.840245, \\
& w_{4}=-0.035069, w_{5}=-0.587439,
\end{aligned}
$$

After judging and calculating the aforementioned properties of the molecule, the binding of the herbal medicine compound and the SARS-CoV-2 protein is calculated using the scoring function (Eq. 9), and the coefficients in Eq. 10 are empirical constants from our experiments. When the binding free energy (binding affinity) is less than $-7 \mathrm{kcal} / \mathrm{mol}$, we judge that the compound can effectively bind to the protein because at this time, the ligand-receptor interaction is an integrated equilibrium process and the resulting herbal medicine molecule conformation has the lowest free energy. For SARS-CoV-2 protein with small structures, the entire range is directly framed for docking, and for larger structures, the proteins are divided into multiple regions for docking separately, and then the results are manually combined.

\section{SARS-CoV-2 Protein Docking Process}

First, the aforementioned method is used to dock the herbal medicine and its corresponding compounds (482 herbal medicines and 13,448 compounds) obtained from the TCMSP database with the SARS-CoV-2 proteins (24 proteins) obtained from the RCSB website. We docked the herbal medicine compounds with the SARS-CoV-2 proteins 10 times each and took the average of the 10 times as the docking results. Then the molecular fingerprints and trait characteristics of each herbal medicine are embedded into a vector. Based on the embedded vector, the similarity between each of the 482 herbal medicines and each of the herbal medicine in each prescription of "three TCM prescriptions and three medicines" is calculated by collaborative filtering. Finally, based on the aforementioned "three TCM prescriptions and three medicines" ranking list, the herbal medicine with the highest similarity value is selected and formed into a prescription (i.e., herbal medicine combination). Finally, based on the ranking list of each herbal medicine in each prescription of "three TCM prescriptions and three medicines," the one with the highest similarity value is selected and formed into a prescription (i.e., herbal medicine combination).

\section{Collaborative Filtering}

Collaborative filtering algorithm is one of the more well-known and commonly used recommendation algorithms to predict possible herbal medicine combinations based on the docking results of molecules (Wang and Zeng, 2020). We performed the recommendation of herbal medicine combinations by the collaborative filtering algorithm and added the structural information of the compound itself to the docking values as the auxiliary information of collaborative filtering.

The training set for this task is a list of combinations of specific herbs with 482 herbs in the three-drug triad and their synergistic labels. First, given a drug combination $(x, y)$, a molecular docking technique is used to output their respective vector representation $\mathrm{x}, \mathrm{y}$ as a continuous vector representation $\mathrm{xy}$. This combination vector describes how the two drugs interact through their respective biological targets. This combined vector is then docked to the new crown protein to predict its synergistic effects based on the Bliss score (Bliss, 1939). We used the Bliss score (Bliss, 1939) to predict the synergistic effect of a drug combination. Assuming that drugs $\mathrm{x}$ and $\mathrm{y}$ interact with neocrown proteins as a result of $p_{x}$ and $p_{y}$, then the result of the reaction of drug combination $(\mathrm{x}, \mathrm{y})$ with neo-crown proteins is defined as

$$
e_{x y}=p_{x}+p_{y}-p_{x} p_{y} .
$$

A drug combination is determined to be synergistic if its actual activity $p_{x y}>e_{x y}$. Therefore, we define its synergistic score as (Jin et al., 2021)

$$
s_{x y}=p_{x y}-e_{x y}=p_{x y}-p_{x}-p_{y}+p_{x} p_{y} .
$$

\section{Molecular Fingerprint Calculation}

Two methods, namely, MACCS and RDK, are chosen to extract the structural features of the compounds by molecular fingerprinting. The RDKit algorithm (Coley et al., 2019) is used to check the substructures between minpath and maxpath, and a total of 166 substructures are checked, with a value of 1 if the molecule has substructure and 0 otherwise, and then the substructures are hashed. We also consider three features, namely, atomic type, aromaticity, and type of bond. Under the premise of satisfying the aforementioned conditions, the length of the generated molecular fingerprint is guaranteed to be constant at 2048, and the molecular fingerprints of all the compounds included are accumulated in terms of herbal medicine. The resulting molecular fingerprints are used as the molecular fingerprints of herbal medicine.

\section{Efficacy Characteristics}

The efficacy, pharmacological properties, and meridians of the aforementioned herbal medicine are filtered from the herbnet database of the Institute of Herbal Medicine Information of the Chinese Academy of Traditional herbal medicine, and the information is standardized and transformed into vectors of specific length. The length of the vector is 739 dimensions, of which 40 dimensions are for medicinal properties, 14 dimensions are for meridians, and 685 dimensions are for efficacy. Finally, the vector is converted into a one-hot vector by assigning a value of 1 if the herbal medicine contains features and 0 otherwise. 


\section{Similarity Calculation}

The similarity between herbal medicines is calculated by molecular fingerprints and efficacy traits of herbal medicines. First, the molecular fingerprints of herbal medicines are converted into one-hot vectors and spliced with efficacy shape features, and then tanimoto similarity calculation is performed from which the similarity matrix of herbal medicines is obtained. The tanimoto coefficient can be used to determine the degree of correlation between two herbal medicines.

$$
\begin{aligned}
& \text { Tanimato }(X, Y)=\frac{X \cap Y}{X \cup Y}, \\
& T(x, y)=\frac{x y}{\|x\|^{2}+\|y\|^{2}-x y},
\end{aligned}
$$

where $\mathrm{X}$ and $\mathrm{Y}$ represent the vectors composed of molecular fingerprints and efficacy traits of herbal medicine, respectively. Here, $\mathrm{x}$ and $\mathrm{y}$ are denoted as two vectors, and each element in the set is denoted as a dimension in the vector. In each dimension, the value taken is usually a value between $[0,1]$, xy denotes the vector product, and $\|x\| \hat{2}$ denotes the mode of the vector, that is,

$$
\|\mathrm{x}\|^{2}=\sqrt{\sum_{\mathrm{i}=1}^{\mathrm{n}} \mathrm{x}_{\mathrm{i}}^{2}} .
$$

Then, the similarity among 482 herbal medicines, three TCM prescriptions, and three medicines is calculated, mainly by calculating the similarity between these 482 herbal medicines and each herbal medicine in the formula (i.e., the value corresponding to the herbal medicines-herbal medicines similarity matrix), and the similarity value between the herbal medicine. The formula is obtained by weighting the herbal medicine contained in the formula by the position of the ruler, subject, and coordinator.

\section{Similarity Calculation of Three TCM Prescriptions and Three Medicines}

The similarity between the 482 herbal medicines and the herbal medicines in three TCM prescriptions and three medicines is calculated, and the top 20 herbal medicines with the highest similarity in each Lianhua Qingwen capsule are taken to form a $12 \times 20$ similar herbal medicine matrix, and the proportion of the herbal medicine in this matrix in the guideline-recommended TCM is calculated.

\section{EXPERIMENTAL RESULTS}

\section{Overview of TCM}

The 482 TCMs obtained from the TCMSP database contained a total of 13,448 compounds, of which 3,243 compounds appeared in multiple TCMs, with beta-sitosterol appearing most frequently in 237 herbal medicines, followed by palmitic acid and Sitogluside which appeared in 227 and 180 herbal medicines, respectively. After absorption, distribution, metabolism, and excretion (ADME) screening, 1665 compounds remained, of which 342 compounds are found in multiple herbal medicines, with betasitosterol occurring most frequently in 237 herbal medicines, followed by quercetin and sitosterol, appearing in 178 and 156 herbal medicines, respectively.

\section{Overview of Three TCM Prescriptions and Three Medicines}

There are 49 herbal medicines in the triad of three TCM prescriptions and three medicines, of which 17 herbal medicines appear in multiple formulations, with ephedra, bitter almond, and licorice appearing the most frequently with a total of five occurrences, followed by patchouli with four occurrences. These 49 herbal medicines contain a total of 3289 compounds, of which 760 compounds appeared in multiple herbal medicines, with the most frequent being palmitic acid which appeared in 29 herbal medicines, followed by betasitosterol and CAM, which appeared in 21 and 20 herbal medicines, respectively. After ADME screening, 49 herbal medicines also contain 409 compounds, of which 62 compounds appear in multiple herbal medicines, with the highest number of occurrences being beta-sitosterol in 21 herbal medicines, followed by stigmasterol and kaempferol in 18 herbal medicines, respectively.

\section{Docking Results of All Compounds}

When the compounds are docked to the herbal medicine results without ADME screening, the average of free energy values for 24 proteins is found to be below $-7 \mathrm{kcal} / \mathrm{mol}$ for 3151 compounds, with chelidimerine having the lowest result of $-10.73 \mathrm{kcal} / \mathrm{mol}$. This compound obtained the lowest free energy value in 12 proteins (S, M, N, nsp2, nsp3, nsp6, nsp9, nsp10, nsp12, nsp13, nsp14, and orf6) and is also low in the other 12 proteins, which is present in the Chinese herb C. alba. The next highest free energy is neo-przewaquinone-a with a mean free energy of $-10.21 \mathrm{kcal} / \mathrm{mol}$, which is present in the TCM Salvia miltiorrhiza.

After screening by ADME, there are 388 compounds below $-7 \mathrm{kcal} /$ mol, of which ( $\left.2 \mathrm{aR}, 2^{\prime} \mathrm{R}, 4 \mathrm{R}, 6 \mathrm{aR}, 6 \mathrm{bS}, 8 \mathrm{aS}, 8 \mathrm{bR}, 11 \mathrm{aS}, 12 \mathrm{aR}, 12 \mathrm{bR}\right)-4$ ((S)-2-(2,6-dimethylphenyl) propoxy)-5',5',6a,8a-tetramethyl-8methylenedocosahydro-1Hspiro[pentaleno[2,1-a]phenanthrene-10,2' pyran] has the lowest free energy value of $-9.29 \mathrm{kcal} / \mathrm{mol}$ and is present in the TCM Puncturevine Caltrop Fruit. It is followed by bisindigotin with a free energy of $-9.24 \mathrm{kcal} / \mathrm{mol}$, which is present in the TCM indigoplant and natural indigo.

\section{Docking Results of Compounds in Three TCM Prescriptions and Three Medicines}

Without ADME screening, the results of compound-herbal medicine docking in three TCM prescriptions and three medicines in average over 24 protein free energy values show that 548 compounds are below $-7 \mathrm{kcal} / \mathrm{mol}$, with the lowest result of $-10.21 \mathrm{kcal} / \mathrm{mol}$ for neo-przewaquinone-a. The compound obtained the lowest free energy value in seven proteins (E, nsp4, nsp7, nsp8, orf7a, orf8, and orf10) and is found in the herbal medicine Salvia divinorum. It is followed by Xambioona with a mean free energy of $-8.89 \mathrm{kcal} / \mathrm{mol}$, which is present in the herbal medicine licorice. The top ten compounds with the lowest free energy without ADME screening are shown in Table 2. 
TABLE 3 | Molecular docking results of six different ways of herbal medicine.

\begin{tabular}{|c|c|c|c|c|c|c|}
\hline Strategy & $\begin{array}{l}\text { Original value } \\
+\quad A L L\end{array}$ & $\begin{array}{l}\text { Original value } \\
+\mathrm{AD}\end{array}$ & $\begin{array}{l}\text { Second classification } \\
+ \text { ALL }\end{array}$ & $\begin{array}{l}\text { Second } \\
\text { classification } \\
+ \text { ADME }\end{array}$ & $\begin{array}{l}\text { Relu }+ \\
\text { all }\end{array}$ & $\begin{array}{l}\text { Relu + } \\
\text { ADME }\end{array}$ \\
\hline 1 & Chrysanthemum & Liquoric Root & Liquoric Root & Liquoric Root & Liquoric Root & Liquoric Root \\
\hline 2 & $\begin{array}{l}\text { Chinese Thorowax } \\
\text { Root }\end{array}$ & Lucid Ganoderma & Chinese Rose Flower & Lucid Ganoderma & Chinese Rose Flower & Lucid Ganoderma \\
\hline 3 & Liquoric Root & $\begin{array}{l}\text { Lightyellow Sophora } \\
\text { Root }\end{array}$ & Fiveleaf Gynostemma Herb & Salvia miltiorrhiza & Fiveleaf Gynostemma Herb & $\begin{array}{l}\text { Chinese Rose } \\
\text { Flower }\end{array}$ \\
\hline 4 & Ephedra Herb & $\begin{array}{l}\text { Barbary Wolfberry } \\
\text { Fruit }\end{array}$ & Achyranthes root & Chinese Rose Flower & $\begin{array}{l}\text { Largetrifoliolious Bugbane } \\
\text { Rhizome }\end{array}$ & Salvia miltiorrhiza \\
\hline 5 & Myrrh & Myrrh & $\begin{array}{l}\text { Largetrifoliolious Bugbane } \\
\text { Rhizome }\end{array}$ & Corydalis Corydalis & Achyranthes root & Corydalis Corydalis \\
\hline 6 & Loquat Leaf & Baical Skullcap Root & Lucid Ganoderma & Corynoline & Lucid Ganoderma & Corynoline \\
\hline 7 & Perilla Fruit & Gambir Plant & Loquat Leaf & Chinese Date & Loquat Leaf & Chinese Date \\
\hline 8 & Ginkgo Leaf & Amur Corktree Bark & Myrrh & Myrrh & Ilex latifolia Thunb & Amur Corktree Bark \\
\hline 9 & Lucid Ganoderma & Salvia miltiorrhiza & Ilex latifolia Thunb & $\begin{array}{l}\text { Lightyellow Sophora } \\
\text { Root }\end{array}$ & Ardisia Herb & $\begin{array}{l}\text { Greater Celandine } \\
\text { Herb }\end{array}$ \\
\hline 10 & & $\begin{array}{l}\text { Barbed Skullcap } \\
\text { Herb }\end{array}$ & Ardisia Herb & $\begin{array}{l}\text { Greater Celandine } \\
\text { Herb }\end{array}$ & Myrrh & Myrrh \\
\hline
\end{tabular}

TABLE 4 | Ranking of docking results of three TCM prescriptions and three medicines.

\begin{tabular}{|c|c|c|c|c|c|c|c|}
\hline Sort & Calculation method & $\begin{array}{l}\text { Original value } \\
+ \text { ALL }\end{array}$ & $\begin{array}{l}\text { Original value } \\
\quad+A L L\end{array}$ & $\begin{array}{c}\text { Second } \\
\text { classification + ALL }\end{array}$ & $\begin{array}{c}\text { Second } \\
\text { classification + ALL }\end{array}$ & Relu + all & Relu + ADME \\
\hline 1 & Original value & $\begin{array}{l}\text { Jinhua Qinggan } \\
\text { Granule }\end{array}$ & $\begin{array}{l}\text { Jinhua Qinggan } \\
\text { Granule }\end{array}$ & $\begin{array}{l}\text { Jinhua Qinggan } \\
\text { Granule }\end{array}$ & $\begin{array}{l}\text { Jinhua Qinggan } \\
\text { Granule }\end{array}$ & $\begin{array}{l}\text { Jinhua Qinggan } \\
\text { Granule }\end{array}$ & $\begin{array}{l}\text { Jinhua Qinggan } \\
\text { Granule }\end{array}$ \\
\hline 2 & & Xuebijing & $\begin{array}{l}\text { Lianhua Qingwen } \\
\text { capsule }\end{array}$ & $\begin{array}{l}\text { Lianhua Qingwen } \\
\text { capsule }\end{array}$ & $\begin{array}{l}\text { Lianhua Qingwen } \\
\text { capsule }\end{array}$ & $\begin{array}{l}\text { Lianhua Qingwen } \\
\text { capsule }\end{array}$ & $\begin{array}{l}\text { Lianhua Qingwen } \\
\text { capsule }\end{array}$ \\
\hline 3 & & $\begin{array}{l}\text { Lianhua Qingwen } \\
\text { capsule }\end{array}$ & $\begin{array}{l}\text { Xuanfei Baidu } \\
\text { recipe }\end{array}$ & Xuebijing & Xuanfei Baidu recipe & Xuebijing & $\begin{array}{l}\text { Xuanfei Baidu } \\
\text { recipe }\end{array}$ \\
\hline 4 & & $\begin{array}{l}\text { Qingfei Baidu } \\
\text { Decoction }\end{array}$ & $\begin{array}{l}\text { Qingfei Baidu } \\
\text { Decoction }\end{array}$ & Xuanfei Baidu recipe & Xuebijing & $\begin{array}{l}\text { Xuanfei Baidu } \\
\text { recipe }\end{array}$ & Xuebijing \\
\hline 5 & & $\begin{array}{l}\text { Huashi Baidu } \\
\text { recipe }\end{array}$ & $\begin{array}{l}\text { Huashi Baidu } \\
\text { recipe }\end{array}$ & Huashi Baidu recipe & Huashi Baidu recipe & $\begin{array}{l}\text { Huashi Baidu } \\
\text { recipe }\end{array}$ & $\begin{array}{l}\text { Huashi Baidu } \\
\text { recipe }\end{array}$ \\
\hline 6 & & $\begin{array}{l}\text { Xuanfei Baidu } \\
\text { recipe }\end{array}$ & Xuebijing & $\begin{array}{l}\text { Qingfei Baidu } \\
\text { Decoction }\end{array}$ & $\begin{array}{l}\text { Qingfei Baidu } \\
\text { Decoction }\end{array}$ & $\begin{array}{l}\text { Qingfei Baidu } \\
\text { Decoction }\end{array}$ & $\begin{array}{l}\text { Qingfei Baidu } \\
\text { Decoction }\end{array}$ \\
\hline 1 & $\begin{array}{l}\text { Composing principle } \\
\text { weighted value }\end{array}$ & Xuebijing & $\begin{array}{l}\text { Jinhua Qinggan } \\
\text { Granule }\end{array}$ & Huashi Baidu recipe & Huashi Baidu recipe & $\begin{array}{l}\text { Jinhua Qinggan } \\
\text { Granule }\end{array}$ & $\begin{array}{l}\text { Jinhua Qinggan } \\
\text { Granule }\end{array}$ \\
\hline 2 & & $\begin{array}{l}\text { Jinhua Qinggan } \\
\text { Granule }\end{array}$ & Xuebijing & $\begin{array}{l}\text { Qingfei Baidu } \\
\text { Decoction }\end{array}$ & $\begin{array}{l}\text { Qingfei Baidu } \\
\text { Decoction }\end{array}$ & $\begin{array}{l}\text { Lianhua Qingwen } \\
\text { capsule }\end{array}$ & $\begin{array}{l}\text { Xuanfei Baidu } \\
\text { recipe }\end{array}$ \\
\hline 3 & & $\begin{array}{l}\text { Lianhua Qingwen } \\
\text { capsule }\end{array}$ & $\begin{array}{l}\text { Xuanfei Baidu } \\
\text { recipe }\end{array}$ & Xuanfei Baidu recipe & $\begin{array}{l}\text { Lianhua Qingwen } \\
\text { capsule }\end{array}$ & Xuebijing & Xuebijing \\
\hline 4 & & $\begin{array}{l}\text { Qingfei Baidu } \\
\text { Decoction }\end{array}$ & $\begin{array}{l}\text { Lianhua Qingwen } \\
\text { capsule }\end{array}$ & Xuebijing & Xuebijing & $\begin{array}{l}\text { Xuanfei Baidu } \\
\text { recipe }\end{array}$ & $\begin{array}{l}\text { Lianhua Qingwen } \\
\text { capsule }\end{array}$ \\
\hline 5 & & $\begin{array}{l}\text { Huashi Baidu } \\
\text { recipe }\end{array}$ & $\begin{array}{l}\text { Qingfei Baidu } \\
\text { Decoction }\end{array}$ & $\begin{array}{l}\text { Lianhua Qingwen } \\
\text { capsule }\end{array}$ & Xuanfei Baidu recipe & $\begin{array}{l}\text { Qingfei Baidu } \\
\text { Decoction }\end{array}$ & $\begin{array}{l}\text { Qingfei Baidu } \\
\text { Decoction }\end{array}$ \\
\hline 6 & & $\begin{array}{l}\text { Xuanfei Baidu } \\
\text { recipe }\end{array}$ & $\begin{array}{l}\text { Huashi Baidu } \\
\text { recipe }\end{array}$ & $\begin{array}{l}\text { Jinhua Qinggan } \\
\text { Granule }\end{array}$ & $\begin{array}{l}\text { Jinhua Qinggan } \\
\text { Granule }\end{array}$ & $\begin{array}{l}\text { Huashi Baidu } \\
\text { recipe }\end{array}$ & $\begin{array}{l}\text { Huashi Baidu } \\
\text { recipe }\end{array}$ \\
\hline
\end{tabular}

After ADME screening, 90 compounds are found to be below $-7 \mathrm{kcal} / \mathrm{mol}$, with compound Xambioona having the lowest free energy value. The next compound is 6-(3-oxoindolin-2-ylidene) indolo[2,1-b]quinazolin-12-one with a mean free energy of $-8.51 \mathrm{kcal} / \mathrm{mol}$, which is present in the herbal medicines Panax quinquefolium, Da Qing Ye, and Qing Dai.

\section{Docking Results for Herbal Medicine}

In six separate ways, the results of the top ten are summarized in Table 3.

\section{Docking Results of Three TCM Prescriptions and Three Medicines}

According to the vector value of herbal medicines and the situation of different herbal medicines in the prescription, the weighted average of three TCM prescriptions and three medicines is calculated, respectively. When not weighted according to the composing principle, Jinhua Qinggan granules have the highest vector value regardless of the way they are ranked, followed by the Lianhua Qinggan capsule and Xuebijing. According to the composing principle, Jinhua Qinggan granules have the 


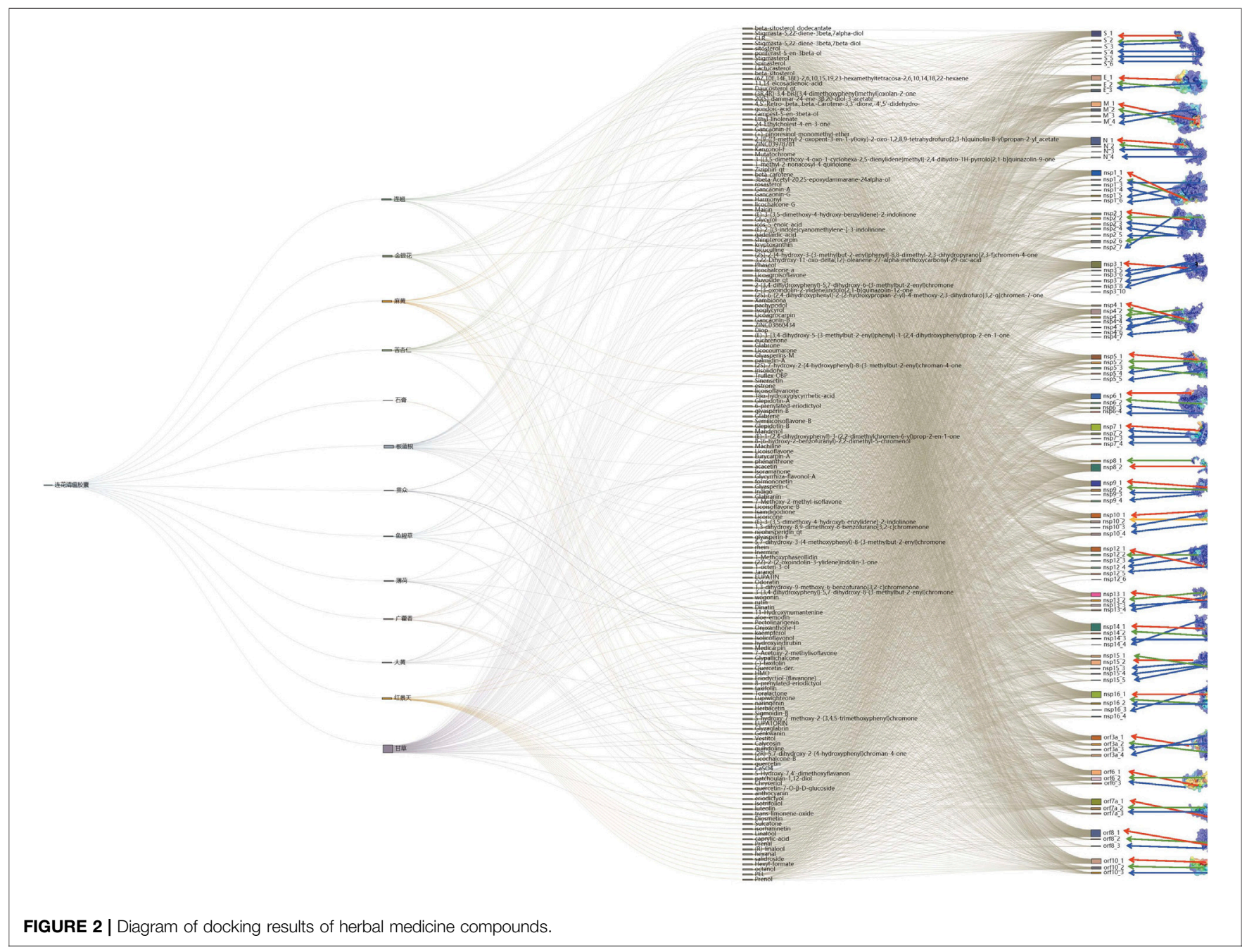

TABLE 5 | Results of collaborative filtration of herbal medicine in Xuebijing.

\begin{tabular}{|c|c|c|c|c|c|}
\hline Index & Red flowers & Chuanxiong & Dan ginseng & Angelica & Red peony \\
\hline 1 & Sand spines & Tiannan star & Tianzhu yellow & Before hu & Man jing zi \\
\hline 2 & Winter flowers & Red flowers & Good mother grass & Caenorhabditis elegans & Summer withered grass \\
\hline 3 & Pepper & Angelica & Tan Xiang & Rose & Qian grass \\
\hline 4 & Ginseng & Winter flowers & Mulberry leaves & Chuanxiong & Bone broken fill \\
\hline 5 & Tiannan star & Chuan Bei mother & Conceptual & Malts & Artemia \\
\hline 6 & Jujube & Lei Gong rattan & Chicken excrement rattan & Chuan Bei mother & Lychee core \\
\hline 7 & Prevent yourself & Before hu & In front of the car & Jujube & Dragon bile \\
\hline 8 & Mulberry leaves & Black beans & Cicc & Red flowers & Chicken vine \\
\hline 9 & Mab & Burdock & Yam & Ginseng & Xin Yi \\
\hline 10 & Before hu & Malts & Guan Huang Bai & The dogwood & Golden buckwheat \\
\hline 11 & Half summer & Chai Hu & Red peony & Sand kernel & Lily \\
\hline 12 & Chuan Bei mother & Pepper & Chun skin & Wu dogwood & West red flowers \\
\hline 13 & Black beans & Half summer & Rohan fruit & Purple Su Zi & Short tea \\
\hline 14 & Acid jujube kernel & Piper seal & Chai Hu & Pepper & Ginkgo leaves \\
\hline 15 & Chuanxiong & Sand spines & Soil tuckahoe & Stemon white & No medicine \\
\hline 16 & Burdock & Lactobacillus & Lei Gong rattan & Big green leaves & Citron \\
\hline 17 & Angelica & Mulberry leaves & Black sesame seeds & Mung bean & White peony \\
\hline 18 & Malts & Amarlane & Pour buckle grass & Quinb & Huang Lian \\
\hline 19 & Orange stalk & Chinese wolfberry & Secret flowers & Cardamom & Guangxi branch \\
\hline 20 & Yam & Calcutrix & The green seal & Ma Huang & Pour buckle grass \\
\hline
\end{tabular}


highest docking value when sorted in three ways. The specific sorting results are shown in Table 4.

\section{Diagram of Docking Results of TCM Compounds}

The distance $-7 \mathrm{kcal} / \mathrm{mol}$ is used as the criterion for whether the receptor protein is bound to the compound. The binding position of the compound and the protein is determined, and the docking sites of the compound on the protein are divided. The results are shown in Figure 2.

\section{Collaborative Filtering Results}

The results of collaborative filtration of herbal medicine in Xuebijing are shown in Table 5. The yellow mark is the herbal medicine in Xuebijing, and each column is arranged from high to low according to the similarity, and the red mark is the herbal medicine appearing in the guide. The principle herbal medicine saxifrage has the highest similarity with safflower. Among the 20 herbal medicines with the highest similarity, six are in the SARSCoV-2-recommended medicines, among which the highest similarity is in the model of winter flowers, followed by ginseng, mulberry leaf, semen, Chuanxiong, angelica, and yam. The herbal medicines with the highest similarity to the subject medicines Chuanxiong and Radix Paeoniae are Tiannanxing and Qianhu, and the first 20 herbal medicines have eight and two herbal medicines in the SARS-CoV-2-recommended herbal medicines, respectively. The herbal medicines with the highest similarity to the adjuvant medicine Dan Shen and Angelicae are Tianzhu Huang and Mang Jiaozi, and five and six herbal medicines are in the SARSCoV-2-recommended herbal medicine, respectively.

The top 20 herbal medicines with the highest degree of similarity between the 12 herbal medicines of Lianhua Qingwen capsule and the 482 herbal medicines docking are shown in Supplementary Table S1. A total of 90 herbal medicines are recommended in the eighth edition of COVID-19 guidelines. The herbal medicine with the highest similarity with Honeysuckle flower in the Lianhua Qingwen capsule is Humulus. Eight of the top 20 herbal medicines are among the recommended herbal medicine of COVID-19, including Weeping Forsythia, Dahurian Patrinia Herb, Common Coltsfoot Flower, Perilla Fruit, Common Anemarrhena Rhizome, Golden Thread, and Great Burdock Achene. Chinese Magnoliavine Fruit is the herbal medicine with the highest similarity to principal herbal medicine, and eight of the top 20 herbal medicines are also among the recommended herbal medicines of COVID-19, including Heartleaf Houttuynia Herb, Golden Thread, Baizhi, Honeysuckle Flower, European Verbena, Immature Bitter Orange, Cassia Twig, and Fortune Eupatorium Herb. The herbal medicines with the highest similarity in the ministerial medicines Bitter Apricot Seed, Gypsum, and Ephedra Herb are Willowleaf Swallowwort Rhizome, Chinese Gall, and Perilla Fruit, respectively, with a total of 13 herbal medicines in the guide. The ministerial medicines Rhubarb, Cablin Potchouli Herb, Peppermint, Cyrtomium Rhizome, Rhodiola, Indigowoad Root, and Heartleaf Houttuynia Herb have the highest similarity, including Chinaberry Bark and Root-bark, Storax, Wild Chrysanthemum, Java Brucea Fruit, Common Selfheal Fruit-
Spike, Indigoplant, and Airpotato Yam Rhizome. A total of 24 herbal medicines are recommended by COVID- 19 .

The top 20 herbal medicines with the highest degree of similarity between the 12 herbal medicines of Xuanfei Baidu prescription and the 482 herbal medicines docking are shown in Supplementary Table S2. Six of the twenty herbal medicines with the highest docking similarity to Ephedra are in the SARS-CoV-2 herbal medicine recommendation guide, among which $\mathrm{Zhi} \mathrm{Mu}$ has the highest similarity to Ephedra, followed by Angelica sinensis, Sheng Jiang, Chuan Xiong, Da Qing Ye, and Hong Hua. Five herbal medicines with the highest similarity to bitter almond, scaphozel, and bitter almond docking, respectively, appeared in the top 20 herbal medicines recommended by SARS-CoV-2, and the highest herbal medicines appearing in the SARS-CoV-2-recommended herbal medicine are $\mathrm{Mu}$ Xiang, Suhe Xiang, and Zhi Mu. The top 20 herbal medicines with the similarity of gypsum did not appear in the SARS-CoV2-recommended herbal medicine.

The top 20 herbal medicines with the highest degree of similarity between the 20 herbal medicines of Qingfei Baidu decoction and 482 herbal medicines docking are shown in Supplementary Table S3. Among the top 20 herbal medicines with the highest docking similarity of Scutellaria baicalensis, Ginger, and Pinellia, eight herbal medicines appeared in the recommended herbal medicines of COVID19 , and the herbal medicines with the highest similarity are Coptis chinensis, Poria cocos, and Astragalus membranaceus. This is followed by Ephedra, Radix et Rhizoma, Zedoary, and Yam, with six of the top 20 herbal medicines with the highest docking similarity appearing in the SARS-CoV2-recommended herbal medicine.

The top 20 herbal medicines with the highest degree of similarity between the 11 herbal medicines of Jinhua Qinggan granule and 482 herbal medicines docking are shown in Supplementary Table S4. The top 20 herbal medicines with the highest docking similarity to Scutellaria baicalensis and Zhi $\mathrm{Mu}$ are the most abundant among the SARS-CoV2-recommended herbal medicines. The herbal medicine with the highest similarity to Scutellaria baicalensis is Huanglian, which is the SARS-CoV-2-recommended herbal medicine. The herbal medicine with the highest similarity to $\mathrm{Zhi} \mathrm{Mu}$ is Polygonum officinale, and the next highest herbal medicine is $\mathrm{Da}$ Qing Ye, which is a SARS-CoV-2-recommended herbal medicine. Forsythia, honeysuckle, and burdock had seven herbal medicines with top 20 similarities in the SARS-CoV2-recommended herbal medicines, respectively. The herbal medicine with the highest similarity in forsythia is northern schisandra, and the herbal medicine with the highest ranking in the SARS-CoV-2-recommended herbal medicine is ichthyopodium. The herbal medicine with the highest similarity to Honeysuckle is Humulus lupulus, and the herbal medicine with the highest similarity in SARS-CoV2-recommended herbal medicine is Forsythia. The herbal medicine with the highest similarity to Burdock is Sandalwood, which also appears in the SARS-CoV2-recommended herbal medicines. 
The top 20 herbal medicines with the highest degree of similarity between the 13 herbal medicines of Huashi Baidu prescription and the 482 herbal medicines docking are shown in Supplementary Table S5. The top 20 herbal medicines with the highest docking similarity to Semen Astragali are the most numerous among the SARS-CoV-2-recommended herbal medicines, with a total of eight herbal medicines. The top two herbal medicines with the highest similarity to Semen Astragali and Sandalwood are both in the SARS-CoV2 -recommended herbal medicine. The next most similar herbal medicine is Ephedra, whose highest similarity is Ziziphi, and the most similar herbal medicine in the SARSCoV-2-recommended herbal medicine is Zhi Mu. Bitter almond, patchouli, scape seed, and Astragalus are among the top 20 herbal medicines with the highest similarity, and five of them appear in the SARS-CoV-2-recommended herbal medicine. The herbal medicine with the highest similarity are Bai Qian, Suhe Xiang, mustard seed, and Han Xia, and the herbal medicine that appeared in the SARS-CoV2-recommended herbal medicine with the highest similarity are $\mathrm{Mu}$ Xiang, Suhe Xiang, Zhi Mu, and Han Xia.

\section{EVALUATION}

Qingfei Baidu decoction, the lung soup, is suitable for light, normal, and heavy patients; Xuanfei Baidu prescription is suitable for normal type of dampness and toxin stagnation of the lung evidence; and Huashi Baidu prescription is suitable for heavy type of epidemic and toxin occlusion of the lung evidence. Lianhua Qingwen Capsule and Jinhua Qinggan granule are indicated for clinical symptoms of malaise with fever during the medical observation period, while Xuebijing is indicated for heavy- and critical-type patients during the clinical treatment period. Our recommended drug combinations can be used and adjusted according to the different clinical manifestations and the actual situation of the patients.

\section{Xuebijing-Recommended Formulas}

Xuebijing-recommended Eq. 1: sea buckthorn, tiannanxing, geranium, antebellum, and bramble seed. Tiannanxing: It is a warming and cold phlegm medicine, with the function of dispelling wind and stopping spasm, warming, and resolving cold phlegm; Tianzhu Huang: clearing heat and resolving phlegm, cooling the heart, and relieving fright; Qianhu: dispersing wind-heat, lowering qi, and resolving phlegm; and Manchuria: dispersing wind-heat and clearing the head and eyes. In summary, our recommended formula can also be used in severe and critical cases of novel coronavirus pneumonia, especially for patients with heavy cough and phlegm.

Xuebijing-recommended Eq. 2: Zanthoxylum, safflower, motherwort, Humulus, and Xia Kuo Cao. Safflower: moisten the lung and lower the Qi, resolve phlegm, and relieve cough; safflower: invigorate blood circulation, dispel blood stasis, and relieve pain; motherwort: invigorate blood circulation, regulate menstruation, diuretic, reduce swelling, clear heat, and detoxify; Xia $\mathrm{Ku}$ Cao: antibacterial action; and Humulus: clear heat and detoxify, diuretic, and laxative; in summary, the recommended formula II is suitable for patients with heavy or critical forms of novel coronavirus pneumonia, or with underlying diseases such as coronary heart disease.

\section{Lianhua Qingwen Capsule-Recommended Formulas}

The recommended formula of Lianhua Qingwen Capsule 1: North Schisandra, Humulus, Bai Qian, Wu Bei Zi, Perilla, Neem Bark, Suhe Xiang, Wild Chrysanthemum, Crow's Nest, White Hair Xia Kuo Cao, Polygonum macrophyllum, Huang Yao Zi, and Perilla (repeated drugs will not be repeated). Humulus: clearing heat and detoxifying, diuretic, and laxative; neem bark: killing insects and healing ringworm; Suhe Xiang: opening the orifice to remove obscenity, opening up phlegm, moving $\mathrm{Qi}$, and relieving pain; Crow's bile: clearing heat, detoxifying, killing insects, and intercepting malaria; white hair Xia Gu Cao: clearing heat and detoxifying, resolving phlegm and relieving cough, cooling blood, and dispersing blood; and yellow herb seed: dispersing knots and eliminating galls, clearing heat and detoxifying, cooling blood, and stopping bleeding.

The recommended formula of Lianhua Qingwen Capsule 2: Gonglao wood, Radix Codonopsis pilosulae, Tianshan snow lotus, Corrugated seeds, Moxa, Mugwort leaf, Semen lily of the valley, Lungwort, Mallow leaf, Big green leaf, Sansho root, and Coriander. Muxiang: Promotes the flow of Qi and relieves pain, regulates the middle, and directs stagnation; Mugwort: warms the menstruation and stops bleeding, disperses cold and pain, dispels dampness, and relieves itching; Lungwort: clears heat and detoxifies the blood, activates blood circulation, and reduces swelling; Malvaceae: clears heat and detoxifies the blood, relieves phlegm, diuresis, and laxative; and Sander root: clears heat and detoxifies the blood, disperses blood stasis, and relieves pain.

\section{Xuanfei Baidu Prescription-Recommended Formulas}

The effects of each drug in the original formula of Xuanfei Baidu prescription include dispelling phlegm, and relieving cough and asthma; moistening the intestines; lowering Qi, opening paralysis, drying dampness, and strengthening the spleen; dispelling wind and dampness; brightening the eyes, activating blood circulation, and dispersing blood stasis; dispelling wind and clearing ligaments; clearing heat and dampness; detoxifying sweating and relieving symptoms; promoting the lung; cooling the blood and stopping bleeding; clearing heat and generating fluid; diuresis and laxative; relieving summer heat; removing steam; aromatizing dampness; harmonizing the stomach and stopping vomiting; dispelling summer heat and relieving toxins; activating blood and clearing menstruation; promoting water retention and decongesting swelling; intercepting malaria, benefiting Qi, and tonifying the middle; relieving pain; moistening the lung relieving cough; diaphoretic and detoxifying; harmonizing various herbs, resolving phlegm and Qi; eliminating food, dipping the lung, and lowering Qi; promoting water retention and swelling; expelling evil and clearing heat from the muscle; and relieving irritation and thirst.

The first group of recommended drug combinations are snake bed seed, white front, chicory, perilla seed, yucca, Xia Gu Cao, 
Suhe Xiang, perilla, and mustard seed, with five times the seed. Among them, the snake bed seeds and mustard seeds dispel wind, Bai Qian and perilla seeds lower qi and relieve cough, chicory and Xia Gu Cao clear heat, Su He Xiang and Pei Lan aromatize dampness, and $\mathrm{Wu}$ Bei $\mathrm{Zi}$ is an astringent to the lung; the drugs in Xuanfei Baidu prescription also have these effects, and the two formulas have similar efficacy.

The second recommended combination of drugs is one branch yellow flower, Tianshan snow lotus, hooked vine, shepherd's purse, coix seeds, Chuan Shao Gan, mugwort leaf, stretching grass, coriander, peony seeds, polygonum grandiflorum, and corrugated seeds. A branch of yellow flower, hooked vine, shepherd's purse, and coix seeds clear heat; Tianshan snow lotus dispels wind; mud bramble calms asthma; mugwort and elongated tendon grass dispel dampness; coriander detoxifies; and corrugated seeds dissolve phlegm. All these recommended drugs are consistent with the effects in the formula.

\section{Qingfei Baidu Decoction-Recommended Formulas}

The effects of each drug in the original formula of Qingfei Baidu decoction include diuresis and dampness, dispersing cold and relieving symptoms, warming the meridians, promoting the flow of Yang and Qi, dispelling phlegm and relieving cough, calming asthma, moistening the intestines, lowering Qi and opening paralysis, permeating dampness and water, strengthening the spleen and stomach, tranquilizing the mind and tranquilizing the spirit, generating sweat and relieving symptoms, promoting the lung and relieving asthma, relieving symptoms and fever, relieving the liver and depression, raising Yang Qi, promoting water and swelling, strengthening the spleen and Qi, drying dampness and water, stopping sweating, aromatizing dampness in the fetus, relieving stomach and vomiting, dispelling summer heat and relieving symptoms, clearing heat and fire, drying dampness and detoxifying the blood, stopping bleeding, moistening the lung, and lowering Qi in the fetus. It is used to relieve phlegm and cough, moisten the lung and lower the qi, relieve phlegm and cough, dispel cold and relieve symptoms, subdue rebelliousness and vomiting, dry dampness and phlegm, subdue rebelliousness and vomiting, eliminate lumpiness and disperse knots, induce diuresis and permeate dampness, relieve heat and promote drenching, tonify the spleen, nourish the lung, consolidate the kidney, benefit the essence, benefit the qi and tonify the middle, relieve acute pain, moisten the lung and relieve cough, relieve fire and detoxify, harmonize all medicines, lower the qi, regulate the middle, awaken the body, dispel cold and wind, relieve pain, warm the lung and dissolve drinks, open the orifices, relieve muscle and clear heat, relieve irritability and thirst, break up Qi and eliminate accumulation, and resolve phlegm and disperse phlegm.

The first group of drug combinations recommended are powdered dioscorea, pepper, Bai Qian, cat's claw herb, Zizyphus, sericea, Suhe Xiang, Ping Bei Mu, Huang Lian, Chang Shan, Tu Fu Ling, Huang Qi, Xuan Shen, Sour date palm, Pei Lan, Atractylodes, and pepper. The drugs include powdered dioscorea, pepper, silkworm sand, Suhe Xiang, Tu Fu Ling, Pei Lan, Atractylodes, pepper to benefit dampness, Bai Qian, purple sage to lower qi, cat's claw herb, Ping Bei Mo, Chang Shan to resolve phlegm, Huang Lian, Xuan Shen to clear heat, Astragalus to strengthen the spleen and benefit qi, and sour date palm to tranquilize the mind, and the original formula has the same effect.

The second group of recommended drug combinations is Panax ginseng flower, Ganoderma lucidum, Tianshan snow lotus, white ganoderma, cape berry, chicken bone herb, mugwort leaf, cornus, northern schisandra, earth maidenha, goldenrod, dried ginger, sandalwood, earth poria, black sesame, coriander, sea gold sand, ganoderma lucidum, and manzanita. Among these medicines, Panax ginseng flower, white creeper, shepherd's purse, chicken bone herb, and earthen berries clear heat; Ganoderma lucidum benefits qi; Tianshan snow lotus dispels wind; mugwort leaf, corn mullein, $\mathrm{Tu}$ Fu Ling, and Hai Jin Sha dispel dampness; northern schisandra, dry ginger, and Ganoderma lucidum strengthen the spleen; Yang Jin Hua and Manshan Hong stop cough; sandalwood stops pain; black sesame benefits essence; and coriander detoxifies toxins. The recommended drugs have the same efficacy as the original formula.

\section{Jinhua Qinggan Granule-Recommended Formulas}

Jinhua Qinggan granule-recommended Eq. 1: five times the seeds, white before, the northern five-flavored seeds, perilla seeds, sandalwood, summer grass, humulus, Huang Lian, wild chrysanthemum, polygonum big green leaf, Celosia, and pelargonium. Wu Bei Zi: Relieve lung and fire, reduce phlegm and drink, relieve cough, dispel the edge, night sweats, vomiting, blood loss, children's night crying symptoms, cure red eyes and dampness, reduce swelling toxin, throat numbness, ulcers, gold sores; Wu Wei Zi: promotes meridians; strengthens the spleen, and opens the stomach; Sandalwood can regulate the Wei Qi and regulate beer lung, and benefit the chest and diaphragm; Xia $\mathrm{Ku}$ Cao: tuberculosis mice with mild reduction in tuberculosis index, lung lesions slightly reduced; Huang Lian: clearing heat and drying dampness, dipping fire and detoxicating. It has a significant inhibitory effect on both positive and negative bacteria in vitro; Daphyllum: clearing heat and detoxifying, cooling blood, and eliminating blemishes; Phellodendron: treating summer exopathogenic, fever, headache, generalized bone pain, stabbing pain in both eyes, chest tightness and nausea, and irregular bowel movement. In conclusion, this recommended formula is suitable for both light and common types of novel coronavirus pneumonia.

Jinhua Qinggan granule-recommended Eq. 2: corrugated seed, Tianshan snow lotus, GongLao wood, Capsella, Qianhu, ChuanShuGan, DangShen, BeiWuYiZi, Half branch lotus, Da QingYe, Tribulus terrestris, and coriander. Daphyllanthus: clearing heat and removing toxins, cooling the blood, and eliminating blemishes; semen lotus: clearing heat and removing toxins, dispersing blood stasis and stopping bleeding, diuretic, and decongesting; Tribulus terrestris: calming the liver, relieving 
depression, dispelling wind, and brightening the eyes; coriander: publishing and penetrating rashes, eliminating food and appetite, relieving pain, and detoxifying. In summary, the recommended formula is suitable for patients with novel coronavirus, mild pneumonia, common type, or with hypertensive underlying disease and concurrent Qi deficiency.

\section{Huashi Baidu Prescription-Recommended Formulas}

The effects of each drug in the original formula of Huashi Baidu prescription include lowering rebelliousness and stopping vomiting; dispersing lumpiness and dissipating knots, drying dampness and warming the middle class, dispelling phlegm and intercepting malaria, benefiting $\mathrm{Q} i$, and tonifying the middle class; relieving urgency and pain; moistening the lung and stopping cough; dipping fire and detoxicating; harmonizing the herbs, dipping the lung, and lowering Qi; dispelling phlegm and calming asthma; inducing diuresis and subduing swelling; expelling and expelling evil, tonifying Qi, and fixing the surface; promoting diuresis; promoting toxicity and draining pus; astringing sores, clearing heat, and cooling the blood; invigorating blood, removing blood stasis, and relieving heat in the muscles; and relieving irritability and thirst.

The recommended first group of drug combinations includes snake's bed sedge, white foreskin, cat's claw herb, red ginseng, perilla seed, neem bark, sulforaphane, Astragalus, persimmon tip, pelargonium, mustard seed, half summer, bramble seed, and fivefold seed. Among them, cat's claw herb and halfsia can dissolve phlegm; red ginseng and Astragalus strengthen the spleen; neem bark, mustard seed, and bramble seed dispel wind; Suhexiang and pelargonium aromatize and dissolve dampness; snake bed seed, bai qian, and persimmon tip lower the qi; and five-fold seed is an astringent to the lung, which are consistent with the efficacy of the original formula and can be recommended.

The second group of recommended drug combinations is one branch of yellow flower, Tianshan snow lotus, white creeper, $\mathrm{Pu}$ huang, shepherd's purse, mullein, mugwort, sandalwood, atractylodes, coriander, polygonum grandiflorum, chicken

\section{REFERENCES}

Ang, L., Song, E., Lee, H. W., and Lee, M. S. (2020). Herbal Medicine for the Treatment of Coronavirus Disease 2019 (COVID-19): A Systematic Review and Meta-Analysis of Randomized Controlled Trials. J. Clin. Med. 9, 1583. doi:10.3390/jcm9051583

Bliss, C. I. (1939). The Toxicity of Poisons Applied Jointly1. Ann. Appl. Biol. 26, 585-615. doi:10.1111/j.1744-7348.1939.tb06990.x

Cavalieri, S., and Rotoli, M. (1997). Huangdi Neijing: a Classic Book of Traditional Chinese Medicine. Recenti Prog. Med. 88, 541-546.

Chan, J. F., Yuan, S., Kok, K. H., To, K. K., Chu, H., Yang, J., et al. (2020). A Familial Cluster of Pneumonia Associated with the 2019 Novel Coronavirus Indicating Person-To-Person Transmission: a Study of a Family Cluster. Lancet 395, 514-523. doi:10.1016/S0140-6736(20)30154-9 bone grass, Xia Ku Cao, and corrugated seeds. Among them, one branch yellow flower, white creeper, shepherd's purse, polygonum officinale, chicken bone herb, and summer cress clear heat; Tianshan snow lotus dispels wind; corrugated root dissolves phlegm; $\mathrm{Pu}$ Huang facilitates water; $\mathrm{Mu}$ Xiang and sandalwood move qi; mugwort and atractylodes dispel dampness; and coriander detoxifies. The efficacy of all these drugs is consistent with the efficacy of the original formula.

In summary, the recommended drugs are consistent with the efficacy of the drugs in the three triads, so the recommended prescription can be considered reasonable from the perspective of Chinese medicine.

\section{DATA AVAILABILITY STATEMENT}

The raw data supporting the conclusions of this article will be made available by the authors, without undue reservation.

\section{AUTHOR CONTRIBUTIONS}

FY, LW, QZ, ZY, FX, and ST conceived the experiments. FY and QZ conducted the experiments. FY, LW, QZ, ST, and FX analyzed the results. FY, LW, and ST wrote the manuscript. LC, QZ, and FX reviewed the manuscript.

\section{FUNDING}

This work was supported by the China Postdoctoral Science Foundation (No. 2019M662373), the National Key Research and Development Program of China (No. 2020YFC2003500), and the National Natural Science Foundation of China (No. 62071278).

\section{SUPPLEMENTARY MATERIAL}

The Supplementary Material for this article can be found online at: https://www.frontiersin.org/articles/10.3389/fphar.2021.759479/ full\#supplementary-material

Chen, Z., and Nakamura, T. (2010). Statistical Evidence for the Usefulness of Chinese Medicine in the Treatment of SARS. Phytother. Res. 18, 592-594. doi: $10.1002 /$ ptr.1485

Coley, C. W., Green, W. H., and Jensen, K. F. (2019). RDChiral: An RDKit Wrapper for Handling Stereochemistry in Retrosynthetic Template Extraction and Application. J. Chem. Inf. Model. 59, 2529. doi:10.1021/ acs.jcim.9b00286

Dhama, K., Sharun, K., Tiwari, R., Dadar, M., Malik, Y. S., Singh, K. P., et al. (2020). COVID-19, an Emerging Coronavirus Infection: Advances and Prospects in Designing and Developing Vaccines, Immunotherapeutics, and Therapeutics. Hum. Vaccin. Immunother. 16, 1232-1238. doi:10.1080/ 21645515.2020.1735227

Dong, M., Zhang, J., Ma, X., Tan, J., Chen, L., Liu, S., et al. (2020). ACE2, TMPRSS2 Distribution and Extrapulmonary Organ Injury in Patients with COVID-19. Biomed. Pharmacother. 131, 110678. doi:10.1016/j.biopha.2020.110678 
Ewing, T., and Kuntz, I. D. (2015). Critical Evaluation of Search Algorithms for Automated Molecular Docking and Database Screening. J. Comput. Chem. 18, 1175-1189. doi:10.1002/(SICI)1096-987X(19970715)18:9<1175:AID-JCC6>3.0.CO;2-O

Hassan, A. S., Askar, A. A., Naglah, A. M., Almehizia, A. A., and Ahmed, R. (2020). Discovery of New Schiff Bases Tethered Pyrazole Moiety: Design, Synthesis, Biological Evaluation, and Molecular Docking Study as Dual Targeting DHFR/ DNA Gyrase Inhibitors with Immunomodulatory Activity. Molecules 25, 11. doi:10.3390/molecules25112593

Huang, C., Wang, Y., Li, X., Ren, L., Hu, Y., Zhang, L., et al. (2020). Clinical Features of Patients Infected with 2019 Novel Coronavirus in Wuhan, China. Lancet 395, 497. doi:10.1016/s0140-6736(20)30183-5

Jin, W., Stokes, J. M., Eastman, R. T., Itkin, Z., Zakharov, A. V., Collins, J. J., et al. (2021). Deep Learning Identifies Synergistic Drug Combinations for Treating COVID-19. PNAS 118, e2105070118. doi:10.1073/pnas.2105070118

Khodair, A. I., El-Barbary, A. A., Imam, D. R., Kheder, N. A., Elmalki, F., and Ben Hadda, T. (2021). Synthesis, Antiviral, DFT and Molecular Docking Studies of Some Novel 1,2,4-triazine Nucleosides as Potential Bioactive Compounds. Carbohydr. Res. 500, 108246. doi:10.1016/j.carres.2021.108246

Li, X., Li, T., and Wang, H. (2020). Treatment and Prognosis of COVID-19: Current S-cenario and P-rospects (Review). Exp. Ther. Med. 20, 1. doi:10.3892/ etm.2020.9435

Li, Q., Guan, X., Wu, P., Wang, X., Zhou, L., Tong, Y., et al. (2020). Early Transmission Dynamics in Wuhan, China, of Novel Coronavirus-Infected Pneumonia. New Engl. J. Med. 382, 1199-1207. doi:10.1056/NEJMoa2001316

Liu, M., Gao, Y., Yuan, Y., Yang, K., Shi, S., Zhang, J., et al. (2020). Efficacy and Safety of Integrated Traditional Chinese and Western Medicine for Corona Virus Disease 2019 (COVID-19): a Systematic Review and Meta-Analysis. Pharmacol. Res. 158, 104896. doi:10.1016/j.phrs.2020.104896

Ning, C., Zou, X., and Xu, L. (2020). Preliminary CT Findings of Coronavirus Disease 2019 (COVID-19). Clin. Imaging 65, 124-132. doi:10.1016/ j.clinimag.2020.04.042

Perico, L., Benigni, A., Casiraghi, F., Ng, L. F. P., Renia, L., and Remuzzi, G. (2021). Immunity, Endothelial Injury and Complement-Induced Coagulopathy in COVID-19. Nat. Rev. Nephrol. 17, 46-64. doi:10.1038/s41581-020-00357-4

Quiroga, R., and Villarreal, M. A. (2016). Vinardo: A Scoring Function Based on Autodock Vina Improves Scoring, Docking, and Virtual Screening. PLoS One 11, e0155183. doi:10.1371/journal.pone.0155183
Remali, J., and Aizat, W. M. (2020). A Review on Plant Bioactive Compounds and Their Modes of Action against Coronavirus Infection. Front. Pharmacol. 11, 589044. doi:10.3389/fphar.2020.589044

Ren, W., Liang, P., Ma, Y., Sun, Q., Pu, Q., Dong, L., et al. (2021). Research Progress of Traditional Chinese Medicine against COVID-19. Biomed. Pharmacother. 137, 111310. doi:10.1016/j.biopha.2021.111310

Shi, Y., Wang, Y., and Shao, C. (2020). COVID-19 Infection: The Perspectives on Immune Responses. [J]. Cell Death and Differentiation 27 (5).

Wang, W., and Zeng, Y. (2020). Collaborative Filtering Recommendation Algorithm Based on Clustering and User Preference. CEA 56, 68-73.

Wölfel, R., Corman, V. M., Guggemos, W., Seilmaier, M., Zange, S., Müller, M. A., et al. (2020). Virological Assessment of Hospitalized Patients with COVID2019. Nature 581, 465-469. doi:10.1038/s41586-020-2196-x

Zeng, M. (2020). Discussion on the Prevention of COVID-19 Based on the Constitutional Theory of Traditional Chinese Medicine (Preprint). doi:10.2196/preprints.19513

Zhao, F., Yang, Z., Wang, N., Jin, K., and Luo, Y. (2021). Traditional Chinese Medicine and Western Medicine Share Similar Philosophical Approaches to Fight COVID-19. Aging Dis. 12, 1162. doi:10.14336/AD.2021.0512

Conflict of Interest: The authors declare that the research was conducted in the absence of any commercial or financial relationships that could be construed as a potential conflict of interest.

Publisher's Note: All claims expressed in this article are solely those of the authors and do not necessarily represent those of their affiliated organizations, or those of the publisher, the editors, and the reviewers. Any product that may be evaluated in this article, or claim that may be made by its manufacturer, is not guaranteed or endorsed by the publisher.

Copyright (c) 2021 Yang, Zhang, Yuan, Teng, Cui, Xue and Wei. This is an openaccess article distributed under the terms of the Creative Commons Attribution License (CC BY). The use, distribution or reproduction in other forums is permitted, provided the original author(s) and the copyright owner(s) are credited and that the original publication in this journal is cited, in accordance with accepted academic practice. No use, distribution or reproduction is permitted which does not comply with these terms. 